\title{
XXXII.
}

\section{Beschreibung und Abbildung eines Apparates zur organischen Elementaranalyse.}

Von

C. M. Warren.

(Mit der Abbildung [auf Taf. 1 am Schluss d. Heftes] vom Verf. aus Proceedings of the americ. acad. of arts and sciences March 8. 1864 . p. 251 mitgetheilt.)

Der Verf. füllt die Verbrennungsröhre locker mit Asbest an und vertheilt dazwischen die zu verbrennende Substanz. Für die Länge der Asbestsäule hat er durch vergleichende Versuche zehn bis zwölf Zoll als das Zweckmässigste gefunden, indem man bei kürzeren Röhren den Gang der Analyse nicht so gut reguliren kann, wenn auch die Verbrennung selbst vollständig ist. Bisher wurde der Apparat nur für flüchtige Körper benutzt, für nichtflüchtige würde jedoch wohl eine kürzere Röhre auch genügen. Um die flüchtige Substanz in die Röhre einzuführen, erhitzt der Verf. ein mit einer Bunsen'schen Lampe verbundenes Stück Kupfer (a), bringt es in die Nähe des hinteren asbestfreien Theiles der Verbrennungsröhre, in welchem sich die Substanz befindet und bringt die letztere zum Verdampfen.

Zuerst wird nun der vordere Theil der Verbrennungsröhre, der Kupferoxyd enthält, erhitzt, alsdann die Destillation nach obiger Weise vorgenommen, wobei sich die Substanz vollständig in den Asbest hineinzieht, und dann der Eintritt des Sauerstoffs bewirkt, nachdem derselbe durch Schwefelsäure (in einem Liebig'schen Kugelapparat sich befindend) durch Natronkalk und Chlorcalcium getrocknet worden ist. Das Kupferoxyd, in gröberen Stücken zwei bis drei Zoll der Röhre ausfüllend, dient dazu, um sich der vollständigen Zersetzung der Substanz versichert halten zu können, ist aber bei Anwendung längerer Röhren selten nöthig. Im Anfange als der Verf. noch mit kürzeren Röhren operirte, war es öfters vorgekommen, dass, durch unvollständige 
Verbrennung sich gasförmige explosive Gemische gebildet hatten, die nicht absorbirt wurden $\mathrm{Um}$ diese Analysen zu retten, wurde das entweichende Gas in der Flasche $C$ aufgefangen und nach beendigter Verbrennung nochmals durch die Röhre geleitet, indem es durch das Queeksilber in $D$ aus $C$ durch die enge Röhre $e$ in die Chlorcalciumröhre $A$ und von da wieder in die Verbrennungsröhre gedrückt wurde. Das jetzt aus dem Apparate entweichende reine Sauerstoffgas wird in einem Gasometer, der bei $c$ statt der zum Auffangen des Gasgemisches erst angebrachten Vorrichtung angesetzt wird, aufgefangen. Doch ist, wie schon oben bemerkt, derselbe $Z$ weck auch durch Anwendung einer längeren Schicht Kupferoxyds einfacher zu erreichen, wenn auch damit einige andere Unbequemlichkeiten verbunden sind.

Die Röhre ist nicht wie gewöhnlich hinten zu einer Spitze ausgezogen, sondern einfach schräg nach oben gebogen, sie wird durch einen durchbohrten Kork geschlossen, durch welchen die mit einer nadelfeinen Oeffnung versehene Röhre $f$ eingefübrt ist. Diese Zuspitzung der Röhre ist deshalb nöthig, um einer etwaigen Diffusion der entstehenden Gase durch den rasch eintretenden Sauerstoffstrom vorzubeugen. In den aufgebogenen Theil der Verbrennungsröhre wird das die zu verbrennende Substanz enthaltende Gläschen gebracht, darin zerbrochen und dann rasch der Kork mit der Zuleitungsröhre vorgelegt. Um aber ganz. sicher zu gehen, wird auch diese ebenfalls mit Asbest gefüllte Röhre während des Verlaufs der Verbrennung erhitzt. Ehe aber diess geschehen kann, muss die Röhre vollkommen durch einen Strom trockner Luft aus dem zweiten Gasometer von Feuchtigkeit befreit und darauf die Luft durch Sauerstoffgas verdrängt werden. Nun werden die Absorptionsapparate vorgelegt, mit dem Gefäss $C$ verbunden und auf ihre luftdichte Verbindung geprüft, indem die Röhre $B$, welche sich in dem sie tragenden Tubulus bewegen lässt, und deren weiterer Theil biegsam ist, gedreht wird. Das ausfliessende Quecksilber sangt dann die Luft nach sich, wenn der Apparat nicht luftdicht schliesst. Nachdem jetzt die bewegliche Röhre wieder nach oben gedreht und die 
Wanklyn: Darstell. d. Valeryls durch Einwirkung $\checkmark$. Natrium etc. 259

Substanz wie oben angegeben, in den hinteren Theil der Röhre gebracht worden, lässt man langsam Sauerstoff zutreten, wobei der. Stand des Quecksilbers in der Röhre $B$ immer so zu reguliren ist, dass derselbe in der letzteren um einen halben Zoll tiefer ist als in $C$. Die Verbrennung geht nun wie gewöhnlich vor sich. Schliesslich ersetzt der Verf. den Sauerstoff wieder durch Luft mittelst des zweiten Gasometers.

\section{XXXIII.}

Ueber die Darstellung des Valeryls durch Einwirkung von Natrium auf baldriansaures AethyI.

$$
\text { Von }
$$

\section{J. Alfred Wanklyn.}

(Journ. of the chemical society. Norbr. 1864.)

Die schon vor länger als 20 Jahren von $L$ öwig und Weidmann veröffentlichten Arbeiten über die Einwirkung von Kalium auf Essigäther, die übrigens wenig Beachtung gefunden zu haben scheinen, ergaben, dass das Kalium zwar sehr energisch auf den Essigäther einwirkt, eine Gasentbindung dabei aber nicht stattindet, sondern sich nur Kaliumalkoholat und das Kalisalz einer merkwürdigen, der Essigsäure nahestehenden Säure bildet. Mit den von Frankland und Kolbe gelegentlich ihrer Untersuchungen über die Alkoholradicale später gefundenen Resultaten stimmte diess nicht überein. So gut wie die Metalle aus Jodäthyl Aethyl abzuscheiden vermögen, konnten sie es wohl auch aus essigsaurem Aethyl und anderen Aethylsalzen isoliren; die Vermuthung lag wenigstens nahe.

Der Verf., welcher die Einwirkung des Natriums auf die Fettsäureäther einer Untersuchung unterziehen will, prüfte dazu zuerst die Richtigkeit obiger Angabe, dass das 